\title{
La evolución del compromiso ético de los trabajadores sociales (1869-2013)
}

Francisco Idareta-Goldaracena*

<francisco.idareta@unavarra.es>

Alberto Ballestero-Izquierdo*

*Dpto. de Trabajo Social, Universidad Pública de Navarra

Artikulu honen xedea da gizarte-langintza sortu zenetik gaur egun arte gizarte-langileen konpromiso etikoaren eboluzioa azaltzea, garai bakoitzean erabiltzaileak jasan izan dituen indarkeria-moduak identifikatuz. Artikulua bitan banatzen da. Batetik, azaltzen ditugu profesionalek erabilitako indarkeriamoduak Eskala, Indizea eta Erabiltzailearen Indarkeria Galdetegia erabiliz (Idareta, 2013). Bigarrenean, identifikatzen ditugu gizartelangintzaren etikaren eboluzioan (lau aroetan zatituta) izandako indarkeria-moduak, hau da, lehenengo biak gizarte-langintza modernoaz ari dira, eta beste bietan gizarte-langintza postmodernoaz. Atal horietako bakoitza egituratzen da azalpen historiko eta filosofiko batean eta horren ondorioz gizarte-langintzan izandako ondorioetan.

\section{HITZ-GAKOAK:}

Lanbideetako etika, gizarte-langintza, burokratizazioa, paternalismoa, paternalismoaren kontra.
El objetivo de este artículo es explicar la evolución del compromiso ético de los trabajadores sociales desde el origen del trabajo social hasta la actualidad, identificando los diferentes tipos de violencia que se han venido ejerciendo sobre el usuario en cada época. El artículo está dividido en dos partes. En la primera, explicamos los diferentes tipos de violencia en los que incurren los profesionales a partir de la elaboración original de la Escala, el Îndice y el Cuestionario de Violencia al Usuario (Idareta, 2013). En la segunda, identificamos los tipos de violencia a lo largo de la evolución (fragmentada en cuatro periodos) de la ética del trabajo social: los dos primeros se refieren al trabajo social moderno; y los dos siguientes, al trabajo social posmoderno. Cada una de estas partes se compone de una exposición del marco histórico-filosófico y de la subsiguiente explicación de su repercusión en el trabajo social.

\section{PALABRAS ClaVe:}

Ética de las profesiones, trabajo social, burocratización, paternalismo, antipaternalismo. 


\section{Introducción}

La ética es consustancial al trabajo social. De hecho, gracias a la ética, las y los profesionales del trabajo social son sensibles a los abusos de poder en los que incurren con sus usuarios. Desde su fundación como disciplina-profesión, el compromiso ético de las y los profesionales del trabajo social ha ido paulatinamente cambiando, debido, en gran medida, al contexto histórico-filosófico de cada época. Un compromiso ético que va ineludiblemente unido a la sensibilidad que cada profesional tiene de identificar los abusos de poder en los que incurre con sus usuarios.

Por ello, hemos fragmentado el artículo en dos partes. En la primera, analizaremos los diferentes tipos de violencia en los que incurren las y los profesionales del trabajo social en su ejercicio habitual, ordenados en la Escala de Violencia al Usuario (EVU), elaborada principalmente a partir de las consideraciones de Emmanuel Lévinas y Jacques Derrida sobre la violencia. En la segunda parte, explicaremos la evolución del compromiso ético de las y los profesionales del trabajo social desde sus orígenes como disciplina-profesión hasta la actualidad, haciendo especial hincapié en las diferentes modalidades de responsabilidad ética por las que ha sido influenciada la ética del trabajo social.

\section{La escala, el índice y el cuestionario de violencia al usuario}

Para elaborar la Escala de Violencia al Usuario (EVU), hemos partido de las perspectivas que tienen tanto Lévinas como Derrida sobre la violencia. Para Lévinas, la violencia no sólo consiste en aniquilar físicamente al Otro, sino en desposeerle de todas las cualidades que lo hacen singular, para sustituirlo por la idea que el sujeto que lo recibe se compone de él. Así, para Lévinas la violencia se encuentra irremisiblemente vinculada a la soledad y sus consecuencias (Lévinas, 1993, 2000a, 2000b, 2001, 2004, 2006a y 2006b): el ensimismamiento egoísta, estar preocupado siempre de uno mismo, olvidarse de los demás...

Esta distancia que se logra establecer con el Otro a través del ensimismamiento, creyéndose que el sujeto vive solo y para sí, le llevan a intelectualizar las relaciones con los objetos y los sujetos del mundo, ante la escasez o ausencia total de experiencias cara a cara con sus congéneres. Así, tanto los objetos como los sujetos del mundo se transforman en ideas suyas a las que los ajusta, creyendo que son de su dominio y propiedad. A la violencia que, según Lévinas, se ejerce ajustando al Otro a la medida de las categorías cognitivas del sujeto que lo recibe, nos referiremos como violencia metafísica. Fue Derrida (1989) el que, en una crítica a la obra del propio Lévinas, se refirió a esta violencia metafísica, que "es irreductiblemente violenta" (Biset, 2007: 133).

Por ello, a partir de la consideración que estos autores tienen sobre la violencia, hemos elaborado una grada- ción de violencias. Según Lévinas, se hace violencia al Otro cuando le imponemos nuestro criterio sin respetar su decisión autónoma o siendo indiferentes para con él. Según Derrida, violentamos al Otro al ajustarlo a la medida de nuestras categorías cognitivas. No en vano, es esta violencia cognitiva la que predispone y prepara al sujeto para la violencia de facto.

Aproximando todo esto al trabajo social, Bermejo (2002) se refiere al paternalismo como imposición del criterio del bienestar del profesional al usuario sin prestar atención a su autonomía, y al antipaternalismo como dejadez en la supervisión del bienestar del usuario por tener en cuenta únicamente su autonomía. Desde la perspectiva levinasiana, las podemos denominar violencias paternalista y antipaternalista. Desde la perspectiva derridiana, si estas violencias se ejercen cuando actuamos, es decir, en la intervención social, las violencias que preparan y que predisponen cognitivamente al profesional a éstas se denominarían violencias metafísicas paternalistas y antipaternalistas. Mientras que las primeras se caracterizan por que se llevan a cabo de facto en la intervención social, las segundas se originan cognitivamente, ajustando al usuario a la medida de las categorías cognitivas del profesional, principalmente, a la hora de realizar el diagnóstico, la planificación y la evaluación social.

Por otra parte, a la hora de elaborar la EVU, hemos partido de considerar que el dilema ético más característico del trabajo social se origina entre los principios éticos de autonomía y de bienestar (Salcedo, 2001a, 2001b, 2010; Ballestero, 2013). Por ello, en lo sucesivo se analiza la violencia al usuario según el grado de prioridad que cada profesional otorgue a cada uno de esos principios en su intervención social. Como se ilustra en las Figuras 1 y 2, la EVU la hemos elaborado situando la violencia paternalista y la antipaternalista en los dos extremos de un eje imaginario.

Así, como anticipábamos, la violencia paternalista consiste en respetar únicamente el bienestar del usuario, sin tener en cuenta ni su opinión ni su decisión autónoma -como se ilustra en la Figura 1, el profesional otorga cuasi absoluta prioridad al principio de bienestar y escasa o nula importancia al principio de autonomía-, mientras que la violencia antipaternalista consiste en respetar la decisión autónoma del usuario, sin tener en cuenta el bienestar que éste se provea a través de aquélla -como se ilustra en la Figura 1, cuasi absoluta prioridad al principio de autonomía, y escasa o nula importancia al principio de bienestar-. Ambas violencias se originan en el trato con el usuario, en la intervención social, y por ello tienen un carácter fáctico.

A continuación, como grados inferiores de violencia aunque predisponentes a la violencia paternalista y antipaternalista, situamos la violencia metafísica paternalista y la antipaternalista. Lo que diferencia a éstas de las anteriores es que son violencias que se ejercen cognitivamente, es decir, cuando el profesional piensa al usuario de forma paternalista 
Figura 1. Representación gráfica de la Escala de Violencia al Usuario (EVU), a partir de los principios éticos de autonomía y de bienestar

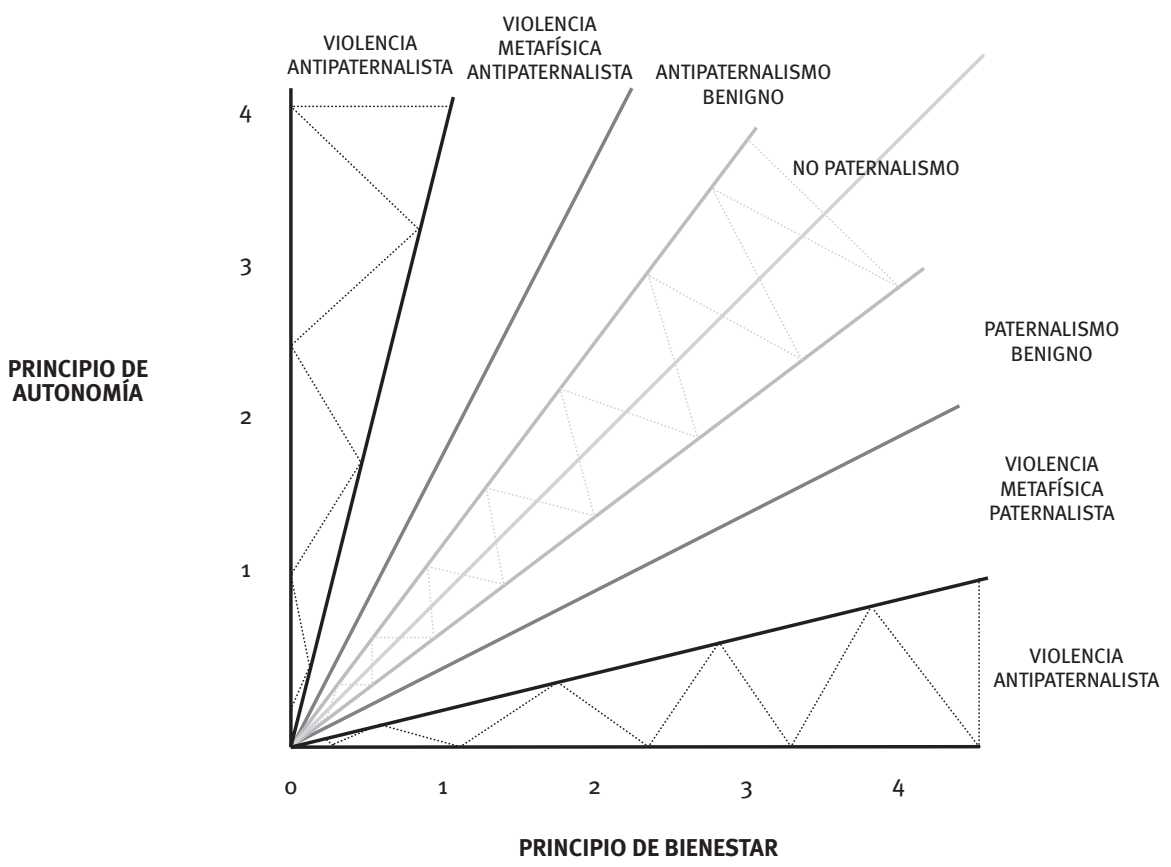

Fuente: Idareta, 2013.

Figura 2. Representación gráfica de la Escala de Violencia al Usuario (EVU)

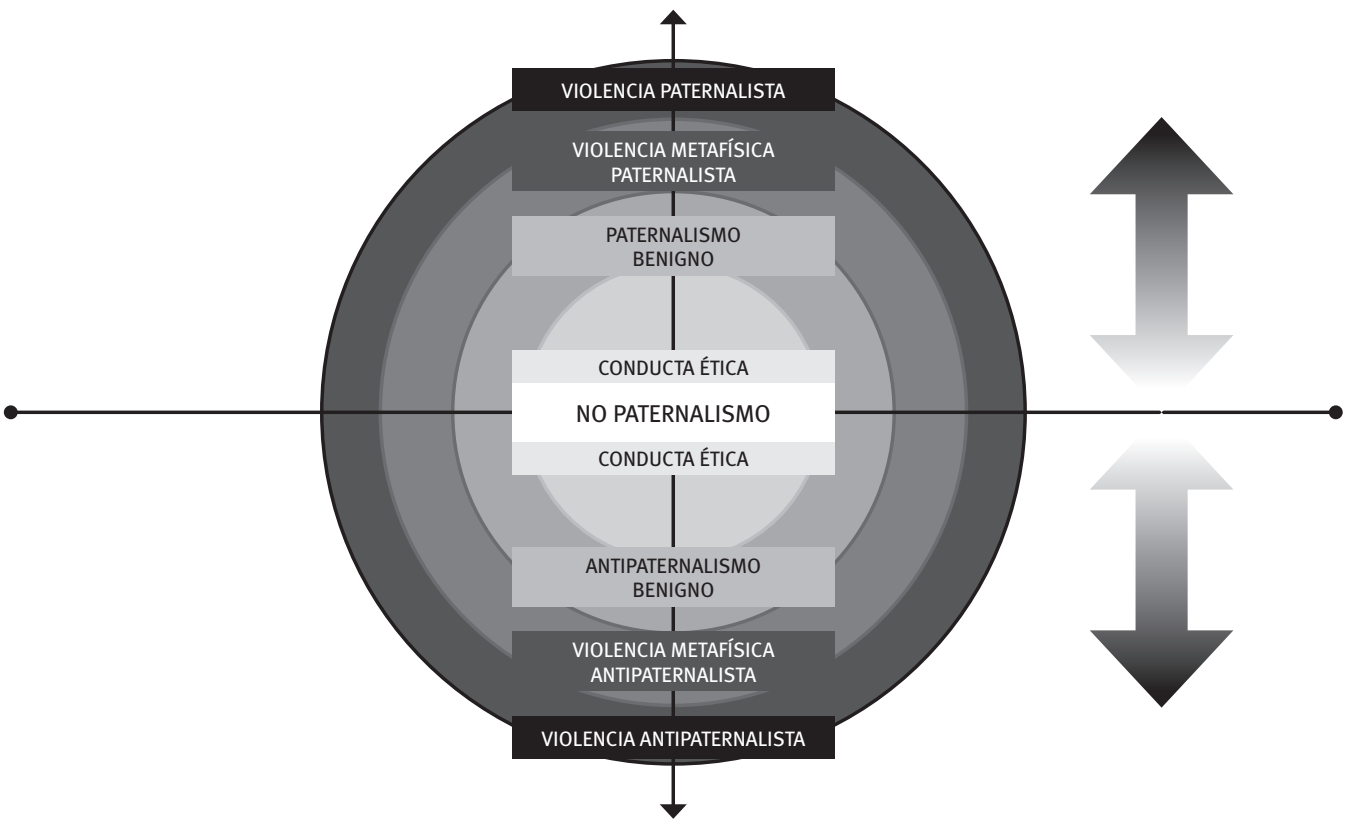

ANTIPATERNALISMO

Fuente: Idareta, 2013. 
0 antipaternalista. Seguidamente, el menor grado de violencia lo hemos representando a través del paternalismo y el antipaternalismo benignos, que consisten en aquellas conductas paternalistas 0 antipaternalistas que, siguiendo las directrices señaladas por algunos de los códigos deontológicos de trabajo social existentes (el de la Federación Internacional de Trabajadores Sociales [FITS] y el de la National Association of Social Workers [NAWS]), están excepcionalmente permitidas al profesional. El punto de equilibrio y de ausencia total de violencia al usuario lo hemos representado a través del no paternalismo (Idareta, 2013).

Por su parte, el Índice de Violencia al Usuario (IVU) tiene como objetivo determinar la frecuencia con la que se experimenta cada uno de los niveles de la EVU. Con el propósito de ayudar a que el profesional identifique cuál es su tendencia habitual en su intervención diaria, hemos elaborado el Cuestionario para la Detección del Índice de Violencia al Usuario (C-IVU). Esta herramienta pretende cuantificar el índice de violencia que el profesional tiende a ejercer sobre el usuario en su ejercicio habitual. Consta de 38 afirmaciones entre las que hay que elegir una respuesta según la frecuencia con la que se experimenta cada ítem. Cada uno de los ítems puntúa individualmente en una escala tipo Likert de 5 puntos, que va desde 'nunca' (puntuado con o puntos) hasta 'siempre' (puntuado con 4 puntos).

Concretamente, la violencia paternalista y la antipaternalista se cuantifican mediante 6 ítems cada una. La primera se mide a través de los ítems 1, 5, 9, 10, 37 y 38 ; mientras que la segunda lo hace a través de los ítems 2, 6, 11, 12, 21 y 22. De ahí que la puntuación que se pueda obtener en cada una oscile entre los o y los 24 puntos. La violencia metafísica paternalista y la antipaternalista se examinan por medio de 6 ítems cada una. La primera se mide a través de los ítems 31, 32, 33, 34, 35 y 36; mientras que la segunda lo hace a través de los ítems 13, 14, 15, 16, 17 y 18. Por ello, el intervalo de puntuación que se puede obtener en cada una se encuentra entre los o y los 24 puntos. El paternalismo benigno y el antipaternalismo benigno se registran mediante 5 ítems cada uno. El primero se mide a través de los ítems 19, 20, 23, 26 y 27; mientras que el segundo se hace a través de los ítems 24, 25, 28, 29 y 30 . De ahí que la puntuación oscile en cada una de ellos entre los o y los 20 puntos. Finalmente, el no paternalismo se detecta mediante 4 ítems $(3,4,7$ y 8$)$, y en esta variable se alcanza una puntuación de entre o y 16 puntos (Idareta, 2013: Tabla 1).

Para conocer el IVU de cada nivel, se suman las puntuaciones de los ítems de cada uno y se divide entre su número total de ítems. Así, el resultado obtenido por cada nivel de la Escala de Violencia al Usuario (EVU) será el Índice de Violencia al Usuario (IVU). Pongamos, por ejemplo, que el profesional obtiene en el nivel violencia metafísica paternalista 3 en el ítem 31, 4 en el 32, o en el 33, 2 en el 34, 1 en el 35 y o en el 36. Dividiremos la suma total de los puntos obtenidos en este nivel $(3+4+0+2+1+0=10)$ entre el número total de ítems de éste (6), con lo que obtendremos su IVU (1'666). Una vez realizada la operación con cada uno de los niveles de la EVU, se compararán las puntuaciones obtenidas y el nivel que alcance en el IVU la mayor puntuación nos dará la medida de la tendencia más habitual del profesional, mientras que el nivel que tenga la menor puntuación indicará la medida de la tendencia más inusual. Para facilitar el cómputo de la puntuación y la obtención del IVU de cada nivel de la EVU, hemos elaborado el Formulario para la Facilitación del Cómputo del IVU (Idareta, 2013: Tabla 2).

\section{Origen y evolución de la ética del trabajo social}

La evolución de la ética del trabajo social la hemos estructurado en cuatro periodos a partir de las clasificaciones realizadas por Diego Gracia (2007) y Frederic Reamer (1998): la acción responsable, el imperativo de responsabilidad, de la responsabilidad absoluta a la actuación prudente y, finalmente, la resolución de dilemas éticos y la burocratización en el trabajo social (Cuadro 1). Como veremos en lo sucesivo, desde el primero hasta parte del tercer periodo, los profesionales inciden más en la dimensión teleológica. Desde mediados del segundo periodo hasta la actualidad, prevalece la tendencia principialista, es decir, una visión muy deontologista de la moral profesional que posibilita un importante desarrollo de la dimensión deontológica. El periodo comprendido entre los últimos años del tercer periodo y la actualidad se caracteriza por la importancia que comienza a adquirir la dimensión pragmática y, más concretamente, los modelos de resolución de dilemas éticos.

\subsection{La acción responsable en el trabajo social moderno}

En el periodo de entreguerras (1918-1933), los esfuerzos de los filósofos se intensificaron, apelando a las acciones responsables de los ciudadanos para evitar que se volviera a originar otro acontecimiento bélico a gran escala. Cuando se precipitó la Segunda Guerra Mundial (1933-1939), se constató que todas aquellas medidas resultaron un fracaso. Fue una época en la que Max Weber contrapuso la ética de la responsabilidad a la ética de la convicción, es decir, la importancia de la reflexión y la actitud crítica del ciudadano a la hora de hacerse cargo de las consecuencias de sus actos, frente al cumplimiento acrítico, estricto y obediente de los principios rígidos que lo arrastraban al fanatismo más recalcitrante. Otro de los visionarios que anticipó la importancia de la responsabilidad fue Friedrich Nietzsche. Cuando sentencia que "Dios ha muerto", pretende significar que, junto con su muerte, perecen todos los valores absolutos e inamovibles que exigen a todos lo mismo y por igual. Cuando Dios deja de

${ }^{1}$ La expresión original se encuentra en el aforismo 125 de su obra La gaya ciencia (Nietzsche, 2000: 185). 


\begin{tabular}{|c|c|c|c|c|c|c|c|}
\hline \multicolumn{8}{|c|}{ Cuadro 1. Evolución de la ética del trabajo social } \\
\hline \multirow[b]{2}{*}{ Periodos } & \multirow[b]{2}{*}{$\begin{array}{l}\text { Contextos histórico- } \\
\text { filosófico }\end{array}$} & \multirow[b]{2}{*}{$\begin{array}{l}\text { Violencia al } \\
\text { usuario } \\
\text { (problema) }\end{array}$} & \multirow[b]{2}{*}{$\begin{array}{l}\text { Propuesta ética } \\
\text { (solución) }\end{array}$} & \multicolumn{3}{|c|}{ Autores destacados } & \multirow[b]{2}{*}{$\begin{array}{l}\text { Dimensión } \\
\text { ética } \\
\text { predominante }\end{array}$} \\
\hline & & & & Filósofos & $\begin{array}{l}\text { Sociólogos, } \\
\text { psicólogos, } \\
\text { médicos } \\
\end{array}$ & $\begin{array}{l}\text { Trabajadores } \\
\text { sociales }\end{array}$ & \\
\hline $\begin{array}{l}\text { Moralizador } \\
(1869-1933)\end{array}$ & $\begin{array}{l}\text { - Periodo entre la } \\
\text { Primera y la } \\
\text { Segunda Guerra } \\
\text { Mundial. } \\
\text { - Vitalismo. } \\
\text { - Existencialismo. } \\
\text { - Marxismo. } \\
\end{array}$ & Paternalismo & $\begin{array}{l}\text { Acción } \\
\text { responsable }\end{array}$ & $\begin{array}{l}\text { Karl Marx } \\
\text { Max Weber } \\
\text { Friedrich } \\
\text { Nietzsche }\end{array}$ & $\begin{array}{l}\text { George H. } \\
\text { Mead } \\
\text { John Dewey }\end{array}$ & $\begin{array}{l}\text { Mary E. } \\
\text { Richmond } \\
\text { Jane Addams }\end{array}$ & $\begin{array}{l}\text { Dimensión } \\
\text { teleológica }\end{array}$ \\
\hline $\begin{array}{l}\text { Valores } \\
(1947-1960)\end{array}$ & $\begin{array}{l}\text { - Tras la Segunda } \\
\text { Guerra Mundial. } \\
\text { - Holocausto, Gulag, } \\
\text { Guerra Civil. } \\
\text { - Crítica de la razón } \\
\text { instrumental } \\
\text { (Horkheimer). }\end{array}$ & Antipaternalismo & $\begin{array}{l}\text { Imperativo de } \\
\text { responsabilidad }\end{array}$ & & & $\begin{array}{l}\text { Félix Biestek } \\
\text { Muriel } \\
\text { Pumphrey } \\
\text { NASW }\end{array}$ & $\begin{array}{l}\text { Dimensión } \\
\text { teleológica. } \\
\\
\text { Dimensión } \\
\text { deontológica }\end{array}$ \\
\hline $\begin{array}{l}\text { Teorías éticas } \\
(1960-1980) \\
\text { Normas éticas } \\
(1980-2000)\end{array}$ & $\begin{array}{l}\text { - Giro ético del } \\
\text { pensamiento con- } \\
\text { temporáneo hacia } \\
\text { la rehabilitación } \\
\text { de la racionalidad } \\
\text { práctica. }\end{array}$ & $\begin{array}{l}\text { Paternalismo } \\
\text { benigno, } \\
\text { antipaternalismo } \\
\text { benigno }\end{array}$ & $\begin{array}{l}\text { Responsabilidad } \\
\text { absoluta, } \\
\text { actuaciôn } \\
\text { prudente }\end{array}$ & $\begin{array}{l}\text { Aristóteles } \\
\text { Inmanuel } \\
\text { Kant } \\
\text { Emmanuel } \\
\text { Lévinas } \\
\text { Hans Jonas } \\
\text { Karl Otto } \\
\text { Apel } \\
\text { John Rawls } \\
\text { Tom } \\
\text { Beauchamp } \\
\text { James } \\
\text { Childress } \\
\text { Martha } \\
\text { Nussbaum } \\
\text { Carol Gilligan }\end{array}$ & $\begin{array}{l}\text { Diego } \\
\text { Gracia }\end{array}$ & $\begin{array}{l}\text { William E. } \\
\text { Gordon } \\
\text { Charles Levy } \\
\text { Frederic } \\
\text { Reamer } \\
\text { Margaret } \\
\text { Rhodes } \\
\text { Ralph Dolgoff } \\
\text { Frank } \\
\text { Loewenberg } \\
\text { Sarah Banks } \\
\text { Chris Clark } \\
\text { Elaine } \\
\text { Congress }\end{array}$ & \begin{tabular}{|l} 
Dimensión \\
deontológica
\end{tabular} \\
\hline $\begin{array}{l}\text { Resolución } \\
\text { de dilemas } \\
\text { éticos } \\
(2000-2013)\end{array}$ & & $\begin{array}{l}\text { Paternalismo por } \\
\text { burocratización }\end{array}$ & Sensibilidad ética & $\begin{array}{l}\text { María J. Úriz } \\
\text { (EFIMEC) } \\
\text { Joan Canimas } \\
\text { (OEA) } \\
\text { Damián } \\
\text { Salcedo } \\
\text { Francisco J. } \\
\text { Bermejo }\end{array}$ & & $\begin{array}{l}\text { Nuria Cordero } \\
\text { (SEIS) }\end{array}$ & $\begin{array}{l}\text { Dimensión } \\
\text { pragmática }\end{array}$ \\
\hline
\end{tabular}

NASW: National Association of Social Workers. EFIMEC: grupo Ética, Filosofía y Metodología de la Ciencia (Universidad Pública de Navarra). OEA: Observatorio de Ética Aplicada (Universitat de Girona). SEIS: Seminario de Ética de la Intervención Social (Universidad Pablo de Olavide). Fuente: elaboración propia.

hacerse cargo del devenir del mundo, el ser humano pasa a ser el máximo responsable de sí mismo, de sus actos, de su prójimo, de su hábitat, del mundo.

La ética del trabajo social, al igual que la propia disciplina-profesión, surge vinculada a la moralización de los más desfavorecidos, es decir, al trato paternalista de éstos. Efectivamente, en aquella época, las y los profesionales se mostraban igualmente preocupados por la moral de los usuarios que por la suya propia (Reamer, 1998). No en vano, lo prioritario era organizar científicamente la pobreza. Gracias a las enseñanzas de John Dewey, así como a la gran influencia de aportaciones como la de Karl Marx, las y los profesionales del trabajo social comienzan a tener una concepción más estructural de la pobreza, que los impulsa a preocuparse por cuestiones éticas como la promoción de la justicia social. No obstante, todavía es un periodo de mínima sensibilidad ética de las y los profesionales del trabajo social, ya que están más pendientes de que su labor sea científica y neutralice las causas sociales, que de las consecuencias éticas de aquélla en el usuario (Reamer, 1998).
Ésta es una época en la que las y los profesionales del trabajo social comienzan a tomar conciencia de la importancia de delimitar los fines y los objetivos a los que aspiraba la profesión ${ }^{2}$, probablemente, a partir de dejar de radicalizar el exacerbado paternalismo inicial. Es decir, el hecho de reflexionar sobre la justicia social y el bien común o bienestar social, ahondando y delimitando así la dimensión teleológica, les pudo dar la medida del paternalismo que ejercían inicialmente moralizando a sus usuarios. No obstante, la tendencia de las y los profesionales del trabajo social fue peculiar: tras incurrir en un moralismo paternalista inicial, absortos en la importancia que comenzaba a tener en la profesión el contexto estructural como principal desencadenante de los problemas sociales, se pasaron al extremo opuesto:

${ }^{2}$ En esta misma línea, el proyecto más antiguo de elaborar un código de ética se le atribuye a la propia Richmond (Pumphrey, 1959). Aunque no fue el único, ya que se tiene constancia de que los infructuosos intentos de redactar códigos de ética profesional datan de 1919 y se mantienen en el tiempo hasta bien entrados los años cuarenta (Reamer, 1998). 
al antipaternalismo radical. Muchos profesionales comenzaron a considerar que el bienestar social del usuario se alcanzaba luchando por mejorar sus condiciones sociales y no velando por supervisar que el usuario, de forma autónoma, se proveyera de tal bienestar. En estos momentos, la impronta marxista es innegable: había que transformar la injusta estructura social para mejorar las condiciones de vida de los usuarios. Por todo ello, la tendencia antipaternalista pudo ser la consecuencia de que las y los profesionales del trabajo social se centrasen cuasi exclusivamente en esta transformación social.

\subsection{El imperativo de responsabilidad en el trabajo social moderno}

Tras la Segunda Guerra Mundial (1939-1945), entre 1945 y 1960 , debido a que las acciones responsables a las que se apelaba no resultaron efectivas, se comenzó a plantear la responsabilidad como imperativo. Tras las guerras mundiales, el Holocausto, el Gulag, se concluyó que la racionalidad teórica y la instrumental habían resultado insuficientemente humanas. Por ello, a inicios de los años sesenta, se comenzó a ser especialmente sensible a los límites de la racionalidad teórica y de la instrumental. En Totalidad e infinito (1961 [2006a]), Lévinas comenzó a aludir a la violencia que se ejerce a la alteridad cuando la totalizamos, es decir, cuando ajustamos la infinita e irreductible singularidad del Otro a la medida de nuestras categorías cognitivas. Una violencia a la que Derrida calificará como metafísica en su obra Violencia y metafísica (1963 [1989]). En 1964 se promulgó la Declaración de Helsinki, que establecía que el bienestar de los sujetos de investigación nunca debe supeditarse a los intereses de la ciencia. La crítica a la racionalidad instrumental vino, entre otros, de la mano de Theodor Adorno con su obra Dialéctica negativa (1966 [2008]), y de Max Horkheimer con su obra Crítica de la razón instrumental (1969 [2002]). Fue en Alemania, entre los años sesenta y setenta, donde se originó el giro del pensamiento contemporáneo hacia la rehabilitación de la racionalidad ética, recurriendo a propuestas éticas como la de Aristóteles e Inmanuel Kant.

Hasta bien entrada la década de los cincuenta, en el trabajo social no se producen intentos serios de explorar sus valores (Reamer, 1998). De hecho, fue en los años cuarenta cuando los profesionales empezaron a preocuparse mucho más por su moralidad y los valores profesionales que por la de los usuarios. De ahí que nos refiramos a que, en esta época, el trabajo social comenzase a profundizar en su dimensión deontológica. Todo ello se evidencia en las numerosas publicaciones en materia ética registradas durante este periodo: la National Association of Social Workers (NASW) crea su primer código de ética (1947), M. Pumphrey (1959) indaga en los valores del trabajo social, W. Gordon (1965) lo hace en aquellos valores fundamentales que guían el ejercicio profesional y C. Levy (1973) propone por vez primera una tipología de los valores del trabajo social. Tres años más tarde, será este último el que realice para el trabajo social una de las reflexiones más profundas desde el punto de vista ético (Reamer, 1998).

\subsection{De la responsabilidad absoluta a la actuación prudente en el trabajo social posmoderno}

El giro del pensamiento filosófico contemporáneo hacia la rehabilitación de la racionalidad ética llega hasta nuestros días. De ahí que se haya recurrido con frecuencia a las propuestas filosóficas de autores como Lévinas (Conesa, 2008). En este contexto histórico-filosófico específico, podemos evidenciar que la profunda reflexión realizada por pensadores de todo el mundo en favor de la rehabilitación de la racionalidad ética influyó también sustancialmente en el trabajo social. Prueba de ello es la lista de principios éticos elaborada por F. Biestek (1966) a finales de los años cincuenta.

Si retrocedemos algunos años, concretamente a los años cuarenta y cincuenta, el trabajo social moderno se centraba en la unicidad y el valor de la persona, siendo los valores predominantes la autodeterminación, la actitud no enjuiciadora y la confidencialidad. En 1958, la National Association of Social Workers (NASW) establece que el valor central en el trabajo social es "la máxima realización del potencial de cada individuo dentro del contexto de la responsabilidad social”. Comprobamos así la influencia de las teorías éticas de la época en el trabajo social: la responsabilidad social comienza a vertebrar el ejercicio profesional.

En los años sesenta y setenta, los valores profesionales del trabajo social comienzan a regirse por los Derechos Humanos y la justicia social como soporte que les dota de sentido y significado humanizante. Así, a comienzos de los años setenta, surge la bioética, según Gracia, como una modalidad diferente y actualizada de estas éticas de la responsabilidad. Según este autor, la bioética "es una típica ética de la responsabilidad" (Gracia, 2007: 10) en la que han tenido mucho que ver filósofos como K. O. Apel, H. Jonas y Lévinas.

La sensibilidad ética de las y los profesionales del trabajo social alcanza sus máximos históricos en los años ochenta, probablemente, gracias al efecto que tuvo en la profesión el surgimiento de la bioética a comienzos de los años setenta. De ahí que situemos el paradigma posmoderno de trabajo social a partir de esta década (Howe, 1999). En los años ochenta, se profundiza en la aplicación de algunas teorías de justicia social, entre las que destaca la de J. Rawls. En este sentido, las tres obras más importantes e influyentes para el trabajo social desde el punto de vista ético fueron las de Loewenberg y Dolgoff (1982), Reamer (1982) y Rhodes (1986) [cits. en Reamer, 1998]. Son obras en las que, por primera vez, se apela a la filosofía moral y se hace uso de algunas de las teorías éticas más influyentes en el trabajo social. Precisamente por ello, durante este periodo, el trabajo social se encuentra muy centrado en la profundización de su dimensión deontológica. Se trata de unos años en los que se comienza a incidir 
especialmente en la noción de usuario como conciudadano, evitando así los abusos de poder de los profesionales como expertos, al tener que considerarlo como igual y tener que respetar sus derechos como ciudadano (Banks, 1997).

\subsection{La resolución de dilemas éticos y la burocratización en el trabajo social posmoderno}

Los últimos años, desde finales de la década de los noventa hasta la actualidad, se han caracterizado por una importante y profunda reflexión en torno a la ética del trabajo social. Concretamente en España, han destacado las aportaciones de autores como Damián Salcedo (2001a, 2001b, 2010), Francisco José Bermejo (2002), María Jesús Úriz Pemán (2004; Ballestero, Úriz y Urien, 2007; Ballestero, Úriz y Viscarret, 2011, 2012 y 2013), así como las del Observatorio de Ética de la Intervención Social de la Universitat de Girona, dirigido por Francesc Pereda y Joan Canimas, del Seminario de Ética Aplicada a la Intervención Social de la Universidad Pablo Olavide de Sevilla y del grupo de investigación EFIMEC (Ética, Filosofía y Metodología de la Ciencia) de la Universidad Pública de Navarra, pionero a escala estatal en la investigación de la ética de la intervención social, dirigido por María Jesús Úriz Pemán. A escala internacional, continúan destacando las aportaciones de Frederic Reamer (1982, 1998), Chris Clark (2006, 2007), Sarah Banks (1997; Banks y Kirsten, 2012) y Elaine Congress (2008; Congress, Black y Strom-Gottfried, 2009).

Todos ellos, en la actualidad, son referentes indiscutibles en esta materia. Sensibilizan a los profesionales en torno a la importancia de un ejercicio éticamente prudente y responsable, planteando novedosas reflexiones y alternativas éticas en aquella dimensión que menor desarrollo presenta en el trabajo social: la pragmática. Efectivamente, el trabajo social tiene muy desarrolladas la dimensión teleológica y la deontológica, pero apenas la pragmática. De ahí la tendencia de las todavía escasas, pero no menos importantes, investigaciones actuales en esta materia. Los principales temas que se abordan hoy día son: el desarrollo de modelos de resolución de dilemas éticos, las auditorías éticas, la aproximación de diferentes teorías éticas al trabajo social, el estudio de las funciones de los profesionales, la validación y traducción de diferentes herramientas de otras disciplinas afines (psicología, principalmente) para el estudio de aspectos éticos de la intervención en trabajo social, la aplicación de los principios éticos a la intervención social, así como la sistemática reactualización y mejora de los distintos códigos deontológicos existentes.

En 2004, se consolidan los Derechos Humanos y la justicia social como sustratos insoslayables para el trabajo social. Como recoge la Federación Internacional de Trabajadores Sociales (2004: apartado 2), “los derechos humanos y la justicia social constituyen la motivación y la justificación de la acción del trabajo social”. De este modo, "lo que comenzó como una preocupación bastante modesta y superficial [del tra- bajo social] sobre las cuestiones morales en los finales del siglo XIX y XX, se ha convertido en un ambicioso intento de comprender y resolver los complejos problemas éticos [en la actualidad]" (Reamer, 1998: 496).

Uno de los fenómenos que ha marcado significativamente la ética del trabajo social en España a partir de los últimos años ochenta y comienzos de los noventa es la fuerte burocratización. A este respecto, las investigaciones más recientes destacan la amonestación y el paternalismo de las y los profesionales del trabajo social para con el usuario como consecuencia de la lógica burocrática-administrativa (Cañedo, 2011). Estos profesionales se caracterizan por "su escasa consideración del usuario como sujeto agente que puede intervenir sobre su propia problemática” (Cañedo, 2011: 149). Los profesionales del trabajo social en contextos altamente burocratizados como el de los servicios sociales públicos, al estar desbordados por la realización de trámites y formularios por medio de los cuales identificar cuál es la ayuda que se les puede ofrecer a los usuarios (una demanda-tipo con un recurso-tipo), apenas tienen tiempo para el trato personalizado.

A esta presión burocrática, hay que añadirle la lógica impersonal, abstracta y excesivamente técnica y racionalista por el que se rigen los servicios sociales públicos (Cañedo, 2011). La previsible y mecánica lógica burocrática choca frontalmente con la contingencia y la informalidad inherentes a las intervenciones sociales. Es así como la lógica burocrática se normaliza y legitima constantemente: reduciendo al profesional del trabajo social a simple gestor con un tiempo limitado para dedicárselo únicamente a cumplir acrítica y obedientemente con aquello que se le ha encomendado (realización de trámites, cumplimentación de formularios, comprobación de requisitos). A este respecto, cabría señalar que, en la actualidad, se sigue manteniendo la tendencia planteada por la investigación realizada por Salcedo (2001b).

Por todo ello, “la práctica ética debe evitar a toda costa los peligros de la burocratización, actuación impersonal, imparcial y formal que propone una estricta forma de actuar" (Ballestero, Úriz y Viscarret, 2011: 59). No en vano, el profesional que padece esta alta burocratización, pero que es sensible y crítico, es decir, aquel que tiene la ética como primera filosofía, tendrá muchas más posibilidades de evitar intervenir de forma paternalista o antipaternalista con el usuario (Idareta, 2011; Idareta y Ballestero, 2013).

\section{Conclusiones}

Como hemos tenido oportunidad de comprobar, desde sus orígenes hasta la actualidad, el trabajo social se ha regulado, organizado y humanizado gracias a la ética. La ética es tan importante porque sensibiliza a los profesionales en torno a los abusos de poder que pueden cometer y comenten en su ejercicio habitual, instaurando en ellos una actitud crítica y autocrítica permanente. La ética del trabajo social urge siempre y es tan imprescindible porque, 
a la par que sensibiliza a los profesionales, protege a los usuarios de sus abusos de poder, así como de los diferentes tipos de violencia identificados en los que tienden a incurrir. En definitiva, la ética, "savia de la profesión” (Reamer, 1998: 497), logra preservar la auténtica esencia humanizante del trabajo social: la protección de la decisión autónoma del usuario y su bienestar.

\section{Referencias bibliográficas}

ADORNO, T. (2008): Dialéctica negativa, Madrid, Akal.

BALLESTERO, A. (2013): Ética y dilemas éticos en la intervención social desde el Trabajo Social, [tesis doctoral inédita], Pamplona, Universidad Pública de Navarra.

BALLESTERO, A.; ÚRIZ, Ma J.; y URIEN, B. (2007): Dilemas éticos en la intervención social. Una perspectiva profesional desde el Trabajo Social, Zaragoza, Mira Editores.

BALLESTERO, A.; ÚRIZ, Mํㅡ. J.; y VISCARRET, J. J. (2013): "Cuestiones éticas y tipologías del comportamiento ético en la intervención profesional del Trabajo Social", Revista Española de Sociología, nํ19, págs. 67-92.

- (2012): "Funciones profesionales de los trabajadores sociales en España", Cuadernos de Trabajo Social, vol. 26, nํㅜ 1, págs. 127-138.

- (2011): "Cómo resuelven los trabajadores sociales los dilemas éticos", Portularia, vol. 11 no 2, págs. 47-59 [khttp://dx.doi.org/10.5218/ prts.2011.0017)].

BANKS, S. (1997): Ética y valores en el Trabajo Social, Barcelona, Paidós.

BANKS, S.; KIRSTEN, N. (2012): Practising Social Work Ethics around the World: Cases and Commentaries, Nueva York, Routledge.

BERMEJO, F. J. (2002): Ética de las profesiones, Bilbao, Desclée Brower.

BIESTEK, F. P. (1966): Las relaciones de 'casework', Madrid, Aguilar.

BISET, E. (2007): “Jacques Derrida, entre violencia y hospitalidad", Revista de Filosofía, nํㅜ 40, págs. 131-143.

CAÑEDO, M. (2011): ““¿Y esto a quién se lo cuento, al Ayuntamiento?': trabajadores sociales entre la vocación y la burocracia", Cuadernos de Trabajo Social, nํㅡㄹ, págs. 135-153.

CLARK, C. (2007): "Professional responsibility, misconduct and practical reason. Ethics \& Social Welfare, vol. 1, n- 1, 56-75 [<http://dx.doi.org/10.1080/1 7496530701237175>].

- (2006): "Moral character in Social Work”, British Journal of Social Work, vol. 36, nํㅜ 1, págs. 75-89 [〈http://dx.doi.org/10.1093/bjsw/bch364)].

CONESA, D. (2008): “La actualidad de Levinas. Una ampliación ética de la racionalidad teórica”, Pensamiento y Cultura, vol. 11, $\mathrm{n}-2$, págs. 303-312.

CONGRESS, E. (2008): "Comparative codes of ethics", en MIZRAHI, T; y DAVIS, L., Encyclopedia of Social Work, Nueva York, Oxford University Press.

CONGRESS, E.; BLACK, P.; y STROM-GOTTFRIED, K. (eds.) (2009): Teaching Social Work Values and Ethics: A Curriculum Resource, Alexandria, Council on Social Work Education.

DERRIDA, J. (1989): “Violencia y metafísica”, en DERRIDA, J., La escritura y la diferencia, Barcelona, Anthropos, págs. 107-210.

FEDERACIÓN INTERNACIONAL DE TRABAJADORES SOCIALES (2004): La ética en el Trabajo Social. Declaración de principios [<http:// www.pol.una.py/sites/default/files/files/ bienestar/PRINCIPIOS\%20ETICOS\%20DEL\%20 TRABAJ0\%20SOCIAL.pdf〉].

GORDON, W. (1965): “Knowledge and value: Their distinction and relationship in clarifying social work practice", Social Work, vol. 10, no 3 , págs. 32-39.

GRACIA, D. (2007): Fundamentos de bioética, Madrid, Triacastela.

HORKHEIMER, M. (2002): Crítica de la razón instrumental, Madrid, Trotta.

HOWE, D. (1999): “Modernidad, postmodernidad y Trabajo Social”, en SALCEDO, D. (comp.), Los valores en la práctica del Trabajo Social, Madrid, Narcea.

IDARETA, F. (2013): “Propuesta para la medición de la violencia al usuario en el Trabajo Social desde la perspectiva de E. Lévinas y J. Derrida", Portularia, vol. $13, \mathrm{n}$-3 [en prensa]. 
- (2011): La Ética como primera filosofía: aproximación de la Ética de E. Lévinas al Trabajo Social, Saarbrücken, Editorial Académica Española.

IDARETA, F.; y BALLESTERO, A. (2013): “Ética, paternalismo y burocracia”, Portularia, vol. 13, $\mathrm{n}-1$, págs. 27-35 [<http://doi.dx.org/10.5218/ prts.2013.0004)].

LÉVINAS, E. (2006a): Totalidad e infinito: ensayo sobre la exterioridad, Salamanca, Sígueme.

- (2006b): Trascendencia e inteligibilidad: seguido de una conversación, Madrid, Encuentro.

- (2004): Difícil libertad, Madrid, Caparrós.

- (2001): Entre nosotros: ensayos para pensar en otro, Valencia, Pre-Textos.

- (2000a): De la existencia al existente, Madrid, Arena.

- (200ob): Ética e infinito, Madrid, A. Machado Libros.

- (1993): El tiempo y el otro, Barcelona, Paidós.

- (1973): "The value base of social work", Journal of Education for Social Work, ํㅜ 9, págs. 34-42.

LOEWENBERG, F.; y DOLGOFF, R. (1982): Ethical Decisions for Social Work Practice, Itasca, F. E. Peacock.

NATIONAL ASSOCIATION OF SOCIAL WORKERS (2008): Code of Ethics of the National Association of Social Workers [<http://www.naswdc.org/pubs/code/ code.asp?c=sp〉].
NIETZSCHE, F. (2000): La gaya ciencia, Madrid, Espasa Calpe.

PUMPHREY, M. (1959): The Teaching of Values and Ethics in Social Work Education, Nueva York, Council on Social Work Education.

REAMER, F. (1998): “The evolution of Social Work Ethics", Social Work, vol. 43, no 6, págs. 488-500 [/http://dx.doi.org/10.1093/sw/43.6.488〉].

- (1982): Ethical Dilemmas in Social Service, Nueva York, Columbia University Press.

RHODES, M. (1986): Ethical Dilemmas in Social Work Practice, Londres, Routledge \& Kegan Paul.

SALCEDO, D. (2010): “Los fundamentos normativos de las profesiones y los deberes de los trabajadores sociales", Trabajo Social Global, vol. 1, $n^{\circ}{ }_{1}$, págs. 10-38 [rhttp://www.hipatiapress.info/ hpjournals/index.php/tsg/article/view/10/ pdf_4>].

- (2001a): Autonomía y bienestar. La ética del Trabajo Social, Granada, Comares.

- (2001b): “La rebelión ética. Principios del Trabajo Social en el ámbito de la Salud Mental”, Revista Trabajo Social y Salud, no 40, págs. 14-42.

ÚRIZ, Ma J. (2004): “Modelos de resolución de dilemas éticos en Trabajo Social", Revista de Trabajo Social, no 175 , págs. 6-27. 